\title{
Process Window Expansion of Laser Chemical Machining by Using High Pressure
}

\author{
Marcel Simons ${ }^{1}$, Tim Radel ${ }^{1}$, Frank Vollertsen ${ }^{1,2}$ \\ ${ }^{1}$ BIAS-Bremer Institut für Angewandte Strahltechnik, Bremen, Germany \\ ${ }^{2}$ Faculty of Production Engineering-Mechanical Engineering \& Process Engineering, University of Bremen, Bremen, Germany \\ Email:simons@bias.de
}

How to cite this paper: Simons, M., Radel, T. and Vollertsen, F. (2020) Process Window Expansion of Laser Chemical Machining by Using High Pressure. Materials Sciences and Applications, 11, 296-304. https://doi.org/10.4236/msa.2020.115020

Received: March 9, 2020

Accepted: May 5, 2020

Published: May 8, 2020

Copyright (c) 2020 by author(s) and Scientific Research Publishing Inc. This work is licensed under the Creative Commons Attribution International License (CC BY 4.0).

http://creativecommons.org/licenses/by/4.0/

(c) (i) Open Access

\begin{abstract}
Laser Chemical Machining (LCM) is a non-conventional removal process, based on a precise thermal activation of heterogeneous chemical reactions between an electrolyte and a metallic surface. Due to local overheating during the process, boiling bubbles occur, which can impair the removal quality. In order to reduce the amount of bubbles, the laser chemical process is performed at different process pressures. Removal experiments were performed on Titanium Grade 1 using the electrolyte phosphoric acid at various process pressures, machining speeds and laser powers in order to determine the limit of the process window by evaluating the characteristics of the removal cavities. As a result, the process window for non-disturbed laser chemical machining is widened at higher process pressures. The process pressures have no influence on the geometric shape of the removal. The expansion of the process window is attributed to the fact that at higher process pressures the saturation temperature of the electrolyte rises, so that bubble boiling starts at a higher surface temperature on the workpiece induced by the laser power. The removal rate could be increased by a factor of 2.48 by increasing the process pressures from ambient pressure to 6 bar, thus taking an important step towards the economic efficiency of the laser chemical machining.
\end{abstract}

\section{Keywords}

Micro Machining, Laser Micro Machining, Laser Chemical Removal, Removal Rate, Process Pressure

\section{Introduction}

Steadily smaller components increase the demands placed on industrial manufacturing processes. Traditional manufacturing processes are increasingly reaching 
their limits in terms of complexity and size [1]. Alternative machining processes, especially for metallic workpieces, are the so-called non-conventional machining processes. Among other processing methods, laser chemical machining (LCM) is one of them [2].

Laser chemical machining combines the advantages of laser processing, e.g. precise and localized energy input, with the advantages of electrochemical processing with a gentle energy effect without significant heat impact [3], which is why the unprocessed microstructure of the materials is not affected [4]. In laser chemical machining, the workpiece is irradiated with a laser, which introduces local, precise and sufficient energy in the form of heat into the workpiece. The workpiece is surrounded by electrolytes [5].

Depending on the laser intensity used and the spot size of the laser, the induced temperature fields on the workpiece alter the electrochemical potential that induces anodic material resolution, leading to material removal on the surface of the workpiece [6]. Within a suitable process window, a gentle removal is generated without remelting processes in the material, which is the main advantage of laser chemical machining compared to other laser-based non-conventional removal processes [4].

The process window of laser chemical machining is strongly influenced by a variety of mechanisms, such as electrolyte boiling [7], i.e. irregularities in material removal due to excessive line energy [8]. Due to the process window, the removal rates are limited to values as low as $2.4 \times 10^{-5} \mathrm{~mm}^{3} / \mathrm{s}$ for Titanium [9]. The quality of the removals generated depends mainly on the electrolyte boiling within the interaction zone and thus on the shielding effect of the boiling bubbles [9].

In this work, laser chemical machining is performed at different pressures to shift the local electrolyte boiling to a higher temperature range and thereby minimize the shielding effect of the bubble [9] as limiting factors to extend the process window. Different removal experiments with varying process parameters, such as laser power and machining speed at different process pressures were generated. The ablated material was scanned with a confocal microscope and evaluated regarding the removal rate. Furthermore, the removal characteristics were categorized and discussed in relation to the set process parameters especially the process pressure.

\section{Experimental Set-Up}

\subsection{Machining Set-Up and Materials}

A continuous-wave (cw) fiber laser (IPG YLR-100-AC) with a wavelength of $1070 \mathrm{~nm}$ is used as the laser beam source. The Gaussian laser radiation with an optical fiber caliber of $14 \mathrm{~mm}$ is first collimated to a beam diameter of $8 \mathrm{~mm}$, then further reduced to $2 \mathrm{~mm}$ by an inverted telescope and then focused with a lens system with a focal length of $93 \mathrm{~mm}$. With this setup a focus diameter of 25 $\mu \mathrm{m}$ was realized, see Table 1 . 
Table 1. List of process parameters used for experimental investigation.

\begin{tabular}{cccc}
\hline & Parameter & Unit & Value \\
\hline & wavelength & $\mathrm{nm}$ & 1070 \\
Laser beam & laser power & $\mathrm{W}$ & $0.6 \ldots 1.8$ \\
(continuous wave) & focus spot diameter & $\mu \mathrm{m}$ & 25 \\
& processing speed & $\mu \mathrm{m} / \mathrm{s}$ & $50 \ldots 100$ \\
& concentration & $\mathrm{mol} / \mathrm{L}$ & 5 \\
& boiling temperature & ${ }^{\circ} \mathrm{C}$ & 104 \\
Phosphoric acid & transmission coefficient & - & 0.68 \\
$\mathrm{H}_{3} \mathrm{PO}_{4}$ & layer height & $\mathrm{mm}$ & 20 \\
& flow speed & $\mathrm{m} / \mathrm{s}$ & 3 \\
\hline
\end{tabular}

Titanium 3.7024 was selected as workpiece material, with a size of $20 \mathrm{~mm} \times 20$ $\mathrm{mm} \times 1 \mathrm{~mm}$. Before machining, all specimens were ground to ensure the same surface roughness. The reason for this is that bubble nuclei are formed in the recesses of the surface, which is why the number of boiling bubbles is also determined by the surface roughness.

The applied laser powers were chosen so that they will cover all removal regimes at varying process pressures e.g. no removal, non-disturbed removal and disturbed removal.

The workpiece was embedded in a chemical cell flowed through by 5 molar phosphoric acid, see Figure 1. The electrolyte height of approx. $46 \mathrm{~mm}$ affected the power intensity on the workpiece, resulting in a transmission of 0.44 .

During the experiments, the movement of the laser head was ensured by $\mathrm{x}$ and y-axes. For the investigation linear removal lines of $2 \mathrm{~mm}$ length with a machining speed of $50 \mu \mathrm{m} / \mathrm{s}$ and $100 \mu \mathrm{m} / \mathrm{s}$ were generated, see Table 1 .

The current pressure within the cell can be read by a pressure sensor "DMK 351" from "BD-Sensors". With the help of the regulator "KT4" from "Panasonic", the pressure inside the cell can be controlled via a pump connected to a piping system.

\subsection{Definition of Removal Cavity}

The removal cavities were recorded by confocal laser scanning microscopy using the 50X-objective ( 1 pixel $=0.278 \mu \mathrm{m}$ ). The applied confocal microscopic images consisted of $768 \times 2828$ pixels $^{2}$. The analysis software VK is used for processing and exporting the $3 \mathrm{D}$ image information.

With the help of a Matlab program, the 3D information of the individual paths is evaluated, since these mainly store the correlation between induced temperature and the resulting removal. For this purpose, the images are segmented into individual lines perpendicular to the machining speed (x-axis) and then evaluated uniformly. The removal width $\mathrm{w}_{\mathrm{r}}$ and the removal depth $\mathrm{d}_{\mathrm{r}, \max }$ are extracted from the removal profiles, which represent the cross-section profiles of the removal lines. Figure 2 shows the three analysis steps in consecutive order. The measured height data are smoothed using the moving average method. The surface plane $(z=0)$, also called the zero line, is defined by averaging the height values at the corners with $15 \%$ of the pixels. This allows the maximum removal 
depth $d_{r, \max }$ to be determined. The height data between $0.5 d_{r, \text { max }}$ and $d_{r, \max }$ are then extracted and fed into a Gaussian function. The removal width $\mathrm{w}_{\mathrm{r}}$ is determined by the distance between the intersections points of the extension of this Gaussian function and the zero line.

The removal area Ar defines the area enclosed by the Gaussian curve between 0 and $\mathrm{d}_{\mathrm{r}, \max }$. To determine the removal volume, the removal area was multiplied by the pixel size in $\mathrm{x}$-direction (machining direction), see Figure 2. A constant removal along a pixel was assumed. This process was performed for all 2D-removal profiles along the $\mathrm{x}$-axis of the removal paths in an automated loop. At the end of a sequence, the time series provided a mean value with confidence interval for the characteristic parameters removal depth in the center of the removal path the removal width $W_{r}$ and a value for removal volume $V_{r}$

These values allowed the calculation of the removal rate $V_{r}$ according to Equation (1), where $I_{r}$ stands for the length of the removal length.

$$
v_{r}=\left(V_{r} / L_{r}\right) * v_{s}
$$

\subsection{Categorization of the Removal}

As already mentioned, the laser chemical machining is strongly limited by the process window [8]. The quality of the resulting cavities therefore depends strongly on the process parameters, the laser power and the machining. The resulting cavities are divided into three categories, which are summarized in Figure 3.

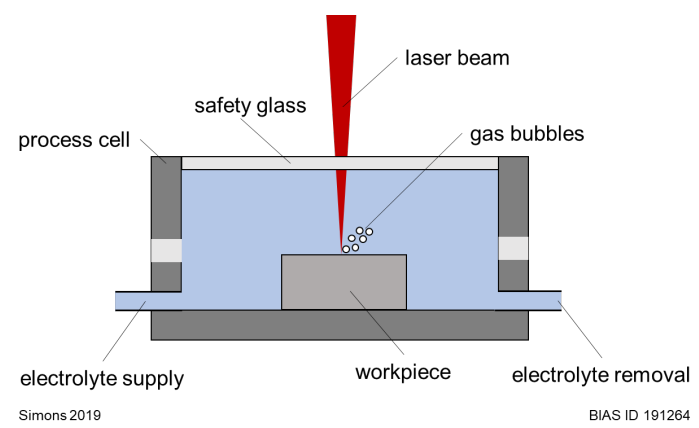

Figure 1. Schematic representation of the experimental set up.

Definition of removal depth

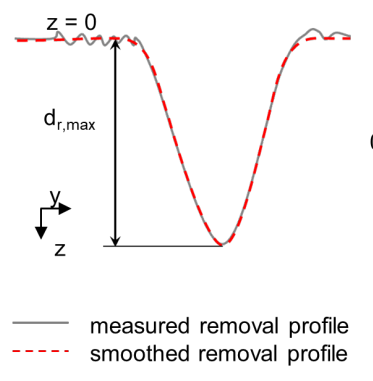

Simons 2019
Definition of removal width

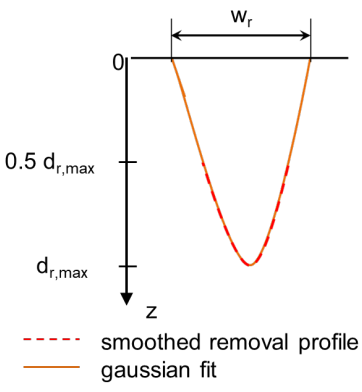

Definition of removal volume

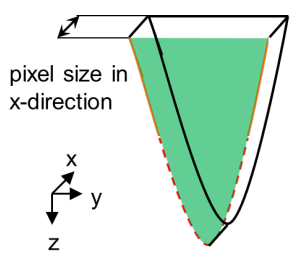

smoothed removal profile

gaussian fit

removal area

Figure 2. Sequence for determining the cavity characteristics adapted from [9]. 


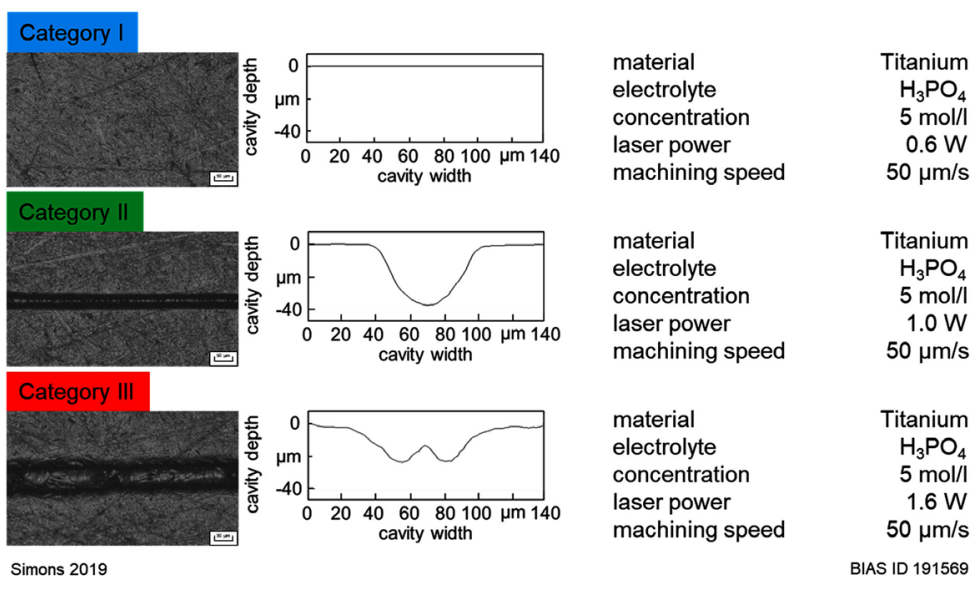

Figure 3. Classification of the removal regime during laser chemical inspired by [9].

No material removal is visible in category 1 . By increasing the laser power a removal becomes visible in category 2. Its shape is similar to a Gaussian profile. Category 3 is achieved by further increasing the laser power. Here the removal is disturbed, and the removal profile is $\mathrm{W}$-shaped, see Figure 3.

Based on the categories defined above, the removal geometries are characterized and the process windows of the laser chemical machining are analyzed under different process pressures. For this purpose, the regime no removal is marked blue, the undisturbed removal green and the disturbed regime red. It is important that a laser power of up to $3 \mathrm{~W}$ produces a purely chemical removal and no thermal removal. Thermal removal negates the advantages of laser chemical machining, such as no influence on the microstructure. Based on [10] the removal image does not show any thermal influence on the sample, so that melting of the surface can be ruled out.

\section{Results}

Figure 4 shows the characteristics of the process window at different process pressures and machining speeds. An extension of the undisturbed removal regime at higher process pressures can be seen. The undisturbed removal regime (marked green) grows. The varying process pressure has no effect on the first regime (marked blue) with no removal.

As can be seen, the undisturbed removal regime is greater at the slower machining speed of $50 \mu \mathrm{m} / \mathrm{s}$. The disturbed removal regime is the starts at the same laser power for both machining speeds. This observation can be seen analogously at all applied process pressures.

Figure 5 shows details of the removal results which defined the process windows shown in Figure 4. At a laser power of $0.4 \mathrm{~W}$, no removal can be detected at all process pressures, as in Figure 4. At a laser power of $1 \mathrm{~W}$, on the other hand, a Gaussian removal profile can be detected which corresponds to the undisturbed removal regime. At a laser power of $1.6 \mathrm{~W}$, a W-shaped profile can be recognized at a process pressure. This indicates a disturbed removal profile. In 
comparison, an undisturbed removal can be detected at a laser power of $1.6 \mathrm{~W}$ and a process pressure of 3 bar or 6 bar. This means that the process window has expanded compared to machining at 1 bar. If one compares the removal profile at $2.2 \mathrm{~W}$, a W-shaped cavity can be detected at 1 bar and 3 bar process pressure. In contrast, at a process pressure of 6 bar a less distorted cavity is visible. A further expansion of the process window between 3 bar and 6 bar process pressure has taken place.

Figure 6 shows the maximum removal rates of the undisturbed removal regime for the applied machining speeds.
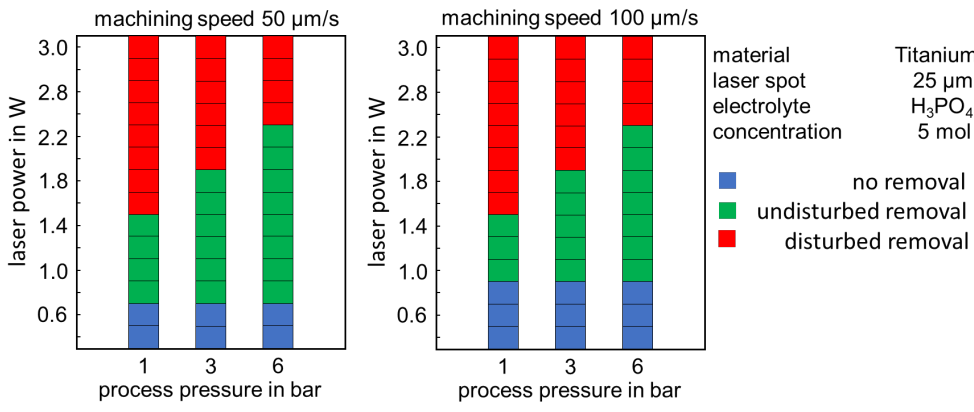

Figure 4. Representation of the laser chemical process window at different process pressures.

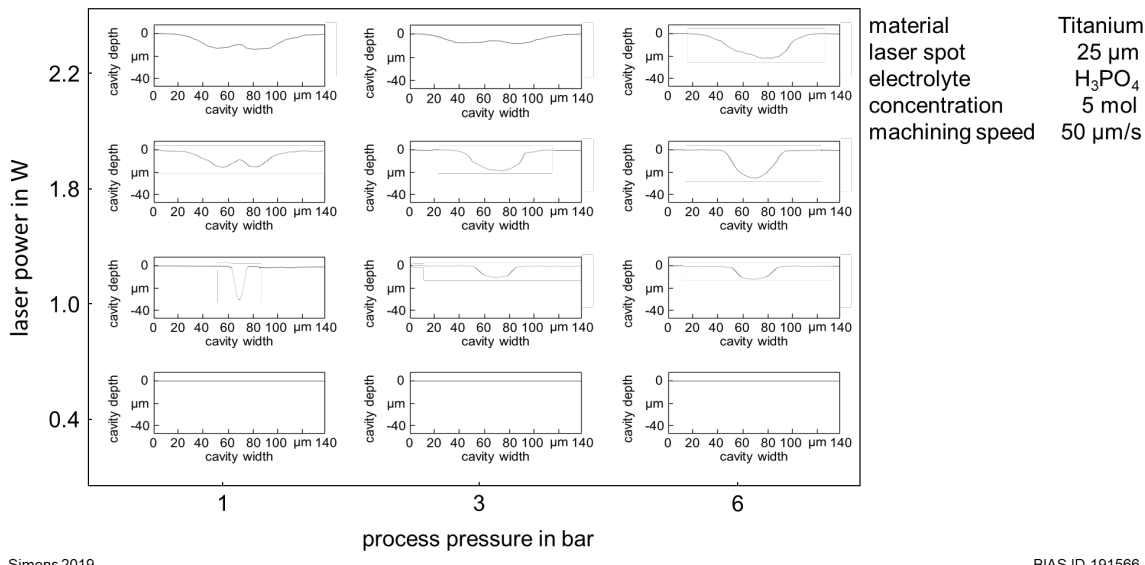

Figure 5. Removal cavities at different laser powers and process pressures.

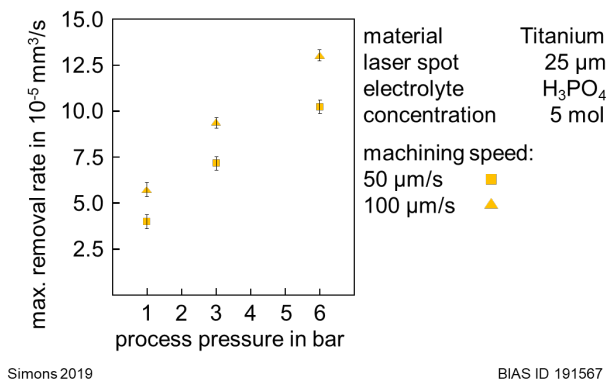

Figure 6. Maximum removal rates of laser chemical machining. 
Due to the extension of the process window, the maximum possible removal rates of the undisturbed removal regime increase, resulting in an increase of the maximum removal rate at a machining speed of $50 \mu \mathrm{m} / \mathrm{s}$ by a factor of 2.48 .

\section{Discussion}

In this work the influence of increased process pressures on the laser chemical process was investigated, in order to increase the process window, see Figure 4.

Figure 7 shows the boiling points of water at different process pressures [11]. In this case, the boiling points of water were used because phosphoric acid is an aqueous solution, having a boiling point close to that of water, see Table 1 . In addition, the maximum surface temperatures are shown based on Figure 4 and calculations of [8], up to which an undisturbed removal was observed in the experiments. This is given for a laser power of $1.4 \mathrm{~W}, 1.8 \mathrm{~W}$ and $2.2 \mathrm{~W}$, respectively. The (calculated) surface temperature at the upper limit of the process window, i.e. in the undisturbed regime, is above the boiling temperature of the electrolyte. This implies that undisturbed removal is possible even if boiling bubbles are present. The quality of the laser chemical removal depends on the bubble size and the time in which the bubbles adhere to the workpiece [12].

The overheating of the surface compared to the boiling temperature is $85 \mathrm{~K}$ at all applied process pressures, see Figure 7. This entails that the process window limiting temperature of the boiling bubble formation [9], which causes removal disturbances due to its shielding, does not set in until a local overheating of $85 \mathrm{~K}$, regardless of the process pressure.

An increase in process pressure thus leads to an increase in the boiling temperature of the electrolyte, see Figure 7. Due to the constant overheating, the maximum surface temperature on the workpiece could be increased by increase of the boiling temperature of the electrolyte $(59 \mathrm{~K})$. Considering the correlation between induced surface temperature and removal rate [8], the removal rate can be increased with increasing maximum surface temperature. This results in an extension of the process window.

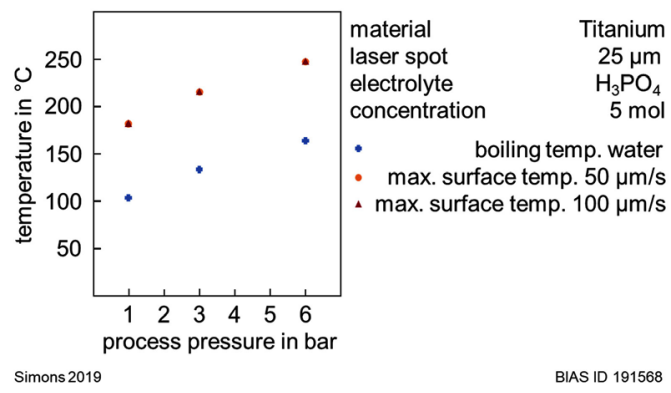

Figure 7. Display of the boiling point of water and maximum surface temperature at different process pressures. The maximum surface temperatures are almost equal for the different machining speeds. 


\section{Conclusion}

To extend the laser chemical process window, the machining is carried out at increased process pressures. By machining at process pressures of up to $6 \mathrm{bar}$, the maximum possible surface temperature could be increased by $59 \mathrm{~K}$. Since the removal rate correlates directly with the induced surface temperature, the removal rate could be increased by a factor of 2.48. Based on the knowledge that the distance of the maximum possible surface temperature is the same regardless of the process pressure, the process window can be calculated for further process pressures.

\section{Acknowledgements}

This work has been funded by the Project 403820352-“Steigerung der Prozesseffizienz der laserchemischen Bearbeitung durch Vermeidung der gasblasenbedingten Abtragsstörungen". The authors gratefully acknowledge the financial support by the Deutsche Forschungsgemeinschaft.

\section{Conflicts of Interest}

The authors declare no conflicts of interest regarding the publication of this paper.

\section{References}

[1] Martin, A. and Fitz Gerald, B. (2013) Process over Platforms-A Paradigm Shift in Acquisition through Advanced Manufacturing. Center for a New American Security, Washington DC

[2] Manjaiah, M., Narendranath, S. and Basavarajappa, S. (2014) Review on Non-Conventional Machining of Shape Memory Alloys. Transactions of Nonferrous Metals Society of China, 24, 12-21. https://doi.org/10.1016/S1003-6326(14)63022-3

[3] Eckert, S. and Vollertsen, F. (2018) Mechanisms and Processing Limits of Surface Finish Using Laser-Thermochemical Polishing. CIRP Annals-Manufacturing Technology, 67, 201-204. https://doi.org/10.1016/j.cirp.2018.04.098

[4] Messaoudi, H., Böhmermann, F., Mikulewitsch, M., von Freyberg, A., Fischer, A., Riemer, O. and Vollertsen, F. (2018) Chances and Limitations in the Application of Laser Chemical Machining for the Manufacture of Micro Forming Dies. MATEC Web of Conferences, 190, 15010. https://doi.org/10.1051/matecconf/201819015010

[5] De Silva, A.K.M., Pajak, P.T., McGeogh, J.A. and Harrison, D.K. (2011) Thermal Effects in Laser Assisted Jet Electrochemical Machining. CIRP Annals-Manufacturing Technology, 60, 243-246. https://doi.org/10.1016/j.cirp.2011.03.132

[6] Bäuerle, D. (2011) Laser Processing and Chemistry. Springer Verlag, Berlin. https://doi.org/10.1016/j.cirp.2011.03.132

[7] Mehrafsun, S. and Vollertsen, F. (2013) Disturbance of Material Removal in Laser-Chemical Machining by Emerging Gas. CIRP Annals, 62, 195-198. https://doi.org/10.1016/j.cirp.2013.03.030

[8] Messaoudi, H., Eckert, S. and Vollertsen, F. (2017) Thermal Analysis of Laser Chemical Machining: Part 1: Static Irradiation. Journal of Materials Science and 
Surface Engineering, 5, 685-691. https://doi.org/10.4236/msa.2017.810049

[9] Mehrafsun, S. and Messaoudi, H. (2018) Dynamic Process Behavior in Laser Chemical Micro Machining of Metals. Journal of Manufacturing and Materials, 2, 54-72. https://doi.org/10.3390/jmmp2030054

[10] Eckert, S., Messaoudi, H., Mehrafsun, S. and Voillertsen, F. (2017) Laser-Thermochemical Induced Micro-Structures on Titanium. Journal of Materials Science and Surface Engineering, 5, 685-691.

[11] Zhang, X., Sun, P., Yan, T., Huang, Y., Ma, Z., Zou, B., Zheng, W., Zhou, J., Gong, Y. and Sun, C.Q. (2015) Water's Phase Diagram: From the Notion of Thermodynamics to Hydrogen-Bond Cooperativity. Progress in Solid State Chemistry, 43, 71-81. https://doi.org/10.1016/j.progsolidstchem.2015.03.001

[12] Simons, M., Radel, T. and Vollertsen, F. (2020) Influence of Laser-Induced Bubble Formation on Laser Chemical Machining. Journal of Surface Engineered Materials and Advanced Technology, 10, 21-33. https://doi.org/10.4236/jsemat.2020.102002

\section{Nomenclature}

$$
\begin{aligned}
& \mathrm{Ar}=\text { removal area } \\
& \mathrm{dr}=\text { removal depth } \\
& \mathrm{lr}=\text { removal length } \\
& \mathrm{vs}=\text { machining speed } \\
& \mathrm{vr}=\text { removal rate } \\
& \mathrm{Vr}=\text { removal volume } \\
& \mathrm{wr}=\text { removal width }
\end{aligned}
$$

